\title{
Upaya Meningkatkan Kinerja Barista Untuk Mengurangi Keluhan Tamu Di Rock Gilis Coffee Lombok
}

\author{
Lutfi Rahman ${ }^{1}$, Emmita Devi Hari Putri ${ }^{2}$ \\ Universitas Bina Sarana Informatika \\ E-mail: emmita.evr@bsi.ac.id
}

\begin{abstract}
The restaurant is a building used to sell food and beverages, equipped with service equipment and provide the best service for guests. The bar running from drinks production to drinks. Poor barista performance can affect the quality of drinks served to guests. The method used in this research is descriptive qualitative and data collection techniques used in this research are observation, interview, documentation and literature study. The results of this study is the performance of baristas are still not good because it does not follow the operational standards that have been set by the company. This is because such as changing the drink recipe that has been provided by the company. By changing the recipe will change the taste of the drink and not in accordance with the standard taste of the drink. In addition, the barista also lacks a sense of responsibility, discipline, initiative and less effective and efficient in working so as to make operations not running smoothly. Services that are still less good to guests cause guests to feel not noticed and will lead to complaints from guests at Rock Gilis Coffee Lombok.
\end{abstract}

\section{Keyword: Barista Perfomance, Guest Complaints, Services}

Abstrak - Restoran adalah sebuah bangunan yang digunakan untuk menjual makanan dan minuman yang dilengkapi dengan peralatan serta memberikan pelayanan terbaik bagi tamu. Salah satunya adalah bar departemen yang menyediakan pelayanan minuman. Bar melayani mulai dari pembuatan minuman sampai dengan menyajikan minuman. Kinerja barista yang kurang baik dapat mempengaruhi kualitas minuman yang disajikan kepada tamu. Metode yang digunakan dalam penelitian ini adalah deskriptif kualitatif dan teknik pengambilan data yang di gunakan dalam penelitian ini adalah observasi, wawancara, dokumentasi dan studi pustaka. Hasil dari penelitian ini adalah kinerja barista yang masih kurang baik karena tidak tidak mengikuti standar operasional yang telah ditetapkan oleh perusahaan. Hal tersebut dikarenakan barista sering mengubah resep minuman yang sudah disediakan oleh perusahaan. Mengubah resep maka akan mengubah rasa minuman dan tidak sesuai dengan standar rasa minuman. Selain itu barista juga kurang mendapatkan motivasi, pelatihan, dan briefing secara rutin untuk meningkatkan semangat bekerja dan meningkatkan kinerja selama operasional berlangsung, barista kurang memiliki rasa tanggungjawab, kedisiplinan, inisiatif dan kurang efektif dan efisien dalam bekerja sehingga membuat operasional tidak berjalan dengan lancar. Pelayanan yang masih kurang baik kepada tamu juga menyebabkan tamu merasa tidak diperhatikan dan akan menimbulkan terjadinya keluhan dari tamu di Rock Gilis Coffee Lombok.

\section{Kata kunci: Kinerja Barista, Keluhan Tamu, Pelayanan}

\subsection{Latar Belakang}

Restoran merupakan suatu jenis usaha jasa pangan dengan peralatan dan perlengkapan untuk proses pembuatan penyimpanan, penyajian, penjualan makanan dan minuman bagi umum yang menempati sebuah bangunan. Restoran pada intinya adalah hospitality industry yang menjual jasa keramah-tamahan. Jasa keramah-tamahan berarti di tuntut adanya hubungan, interaksi dan kontak yang baik antara penyedia jasa sebagai staff dan sebagai pelanggan (KEP.Dirjen Pariwisata No: 15/U/11/1998 Tanggal 25 Februari 1998 dalam Brahmanto, 2018:63).

Rock Gilis Coffee adalah restoran dan industri yang bergerak di bidang usaha makanan dan minuman. Restoran Rock Gilis Coffee mempunyai dua department yaitu Bar dan Kitchen. Bar merupakan bagian dari food and beverage service. Department yang menghasilkan pendapatan terbesar di restoran Rock Gilis Coffee adalah bar. Hal ini dikarenakan bar menjual berbagai macam minuman seperti kopi dan mocktail yang dapat menarik tamu untuk datang ke rock gilis coffee.

Rock Gilis Coffee memberikan kepercayaan kepada barista dalam mengelola bar. Barista adalah seseorang yang bertugas sebagai peracik kopi dan melayani minuman di sebuah bar. Seorang barista bertugas untuk memenuhi permintaan minuman yang di pesan oleh tamu. Barista juga memberikan pelayanan informasi tentang kopi dan promosi menu kepada tamu agar tamu tertarik membeli minuman di Rock Gilis Coffee. 
Kendala yang sering terjadi di Bar Rock Gilis Coffee yaitu salah satu barista tidak mengikuti resep yang sudah disediakan oleh pihak Rock Gilis Coffee, sehingga minuman yang disajikan memiliki rasa yang berbeda dari standar yang seharusnya. Bagi tamu yang sudah terbiasa menikmati minuman tersebut, tentunya akan complaint jika mendapatkan jenis minuman yang biasa di pesan namun memiliki rasa yang berbeda. Hal ini mempengaruhi kinerja barista terutama dalam membuat kopi dan mocktail.

Kendala lain yaitu barista lebih fokus di counter bar dan mengabaikan tamu sehingga barista tidak melakukan quality check terhadap minuman yang dikeluarkan. Beberapa tamu merasa barista kurang konsisten dalam membuat minuman dan memberikan pelayanan yang kurang baik. Setiap tamu atau pelanggan yang datang dengan memesan minuman yang berulang dengan menu minuman yang sama, mulai dari kopi atau minuman yang lain dengan rasa yang berubah-ubah. Upaya meningkatkan kinerja barista untuk mengurangi keluhan terhadap tamu, seorang barista diharapkan dapat mengikuti resep yang sudah disediakan sehingga menciptakan rasa yang sama sesuai dengan standar perusahaan, serta mampu mengelola minuman racikan dan mampu memberikan pelayanan terbaik terhadap konsumen dan terhadap perusahaan. Berkaitan dengan latar belakang masalah yang telah dipaparkan, maka penelitian ini akan mebahas tentang standar operasional prosedur dan standar resep meracik minuman di Rock Gilis Coffee.

\subsection{Kajian Pustaka}

\subsubsection{Ruang Lingkup Restoran}

Restoran adalah suatu tempat atau bangunan yang diorganisasikan secara komersial, mempunyai tujuan mencari keuntungan bagi pemiliknya dengan menyediakan atau menjual makanan minuman, serta memberikan pelayanan terbaik kepada tamunya baik berupa pelayanan makanan maupun minuman (Marsum dalam Darwin dan Hamzah, 2017:12). Restoran adalah suatu industri yang menyelenggarakan pelayanan makanan dan minuman kepada semua orang yang jauh dari rumahnya, maupun yang dekat dari rumahnya (Arief dalam Putri, 2016:72). Seiring berjalannya perkembangan industri dalam penyajian makanan dan minuman, muncul beberapa masalah (Arief dalam Putri, 2016:72) di antaranya:
1. Masalah sanitasi dan hygine dari restoran atau industri penyajian makanan dan minuman.

2. Pengadaan bahan-bahan yang diperlukan oleh industri ini, seperti daging yang bermutu tinggi/baik, bumbu-bumbu atau rempah-rempah yang siap untuk di pakai, dan buah-buahan yang harus di sediakan diluar musimnya.

3. Pendidikan kejuruan di bidang restoran, catering business, termasuk juru masak (cook), restoran manager, waiter-waitress, dan lain-lain.

4. Masalah accounting dan cashiering system, yang sederhana serta dapat di awasi dengan mudah.

5. Cara penciptaan fast food service untuk makanan Indonesia yang dapat dihidangkan secara cepat, serta dengan harga yang terjangkau oleh golongan menengah serta dapat dinikmati (dihidangkan) secara informal.

6. Management yang terpadu secara menyeluruh yang selain akan menjamin kemajuan perusahaan, juga kepuasan dari pelanggan (tamu) yang berkunjung ke restoran tersebut.

\subsubsection{Bar}

Bar dapat di artikan sebagai tempat menjual dan menyajikan minuman yang mengandung alkohol seperti bir, anggur, liqeur, dan cocktail yang bisa di minum di tempat itu juga (Sumarsono, 2015:10). Tetapi bar juga menyediakan minuman yang tidak mengandung alkohol. Istilah bar berasal dari kata barrier berarti sesuatu yang menjadi pemisah atau menghalangi, wujudnya berupa kayu pemisah bisa berupa meja panjang sebagai batas antara pekerja bar (bartender) dan pelanggan atau tamunya (Sumarsono, 2015:10). Kayu pemisah yang biasanya sekaligus berfungsi sebagai meja, dinamakan counter. Counter tersebut biasanya dilengkapi dengan kursi tinggi yang di sebut bar stools. Di bar tamu dapat duduk santai memesan makanan dan minuman yang diinginkannya. Counter juga bertujuan untuk menghindari dan menjaga tamu yang mabuk masuk ke dalam bar dan mengambil minuman maupun merusak peralatan yang ada di bar (Sumarsono, 2015:10). Bar digolongkan menjadi beberapa macam atau jenis sesuai dengan tempat dan fungsinya (Sumarsono, 2015:11) yaitu:

1. Public Bar

Bar yang melayani penjualan minuman untuk umum. Bartender dapat langsung berhubungan dengan tamu sambil membuat minuman. Pub berasal dari kata public yang merupakan kependekan dari 
public house. Para pekerja di inggris setelah selesai kerja di kantor biasanya mereka datang ke pub untuk melepaskan lelah sambil menikmati minuman seperti beer dan makanan ringan

2. Service Bar

Posisinya di belakang dan berdekatan dengan dapur, serta room service sebuah hotel. Bartender tidak berhubungan langsung dengan tamu, jenis bar ini tidak di lengkapi dengan bar stools.

3. Snack Bar

Bar ini hanya menjual makanan besar dan minuman ringan

4. Mini Bar

Bar yang berada di dalam kamar hotel dimana minuman alkoholnya dalam bentuk botol kecil, yang ditata di atas meja yang dilengkapi freezer kecil untuk menyimpan minuman lainnya seperti beer, softdrink sehingga tamu dapat mengambil sendiri

5. Pool Bar

Letak bar ini di area kolam renang di suatu hotel. Penjualan minumannya tidak lengkap, terbatas pada bir, minuman ringan, jus, cocktail, juga di sediakan beberapa macam snack, untuk pelayanan bartender di bantu oleh salah satu atau dua orang pelayan. Gelas yang digunakannya biasanya gelas plastik.

6. Portable Bar

Bar yang dapat dipindah-pindahkan atau dibongkar pasang sesuai dengan kebutuhan. Biasanya bar tersebut berupa counter yang diberi roda atau berupa gabungan dari beberapa meja yang digabung dan diatur sehingga membentuk suatu counter. Portable bar ini biasanya digunakan untuk pesta kecil seperti cocktail party, garden party, dan lain lain.

7. Sanken Bar

Bar yang letaknya di ruangan terbuka seperti halaman rumah

8. Expresso Bar

Bar yang terdapat di pelabuhanpelabuhan laut dan udara. Expresso Bar berasal dari italia yang menjual beberapa minuman, Expresso bar banyak ditemui di tempat umum seperti cafe dan penjualan ice cream.

9. Private Bar

Bar yang terdapat di rumah-rumah orang kaya atau orang berada. Minumannya tidak selengkap di bar. Biasanya terbatas pada koleksi pemilik bar. Pelayanannya lansung ditangani oleh tuan rumah atau tamunya sendiri.

10. Lounge Bar

Bar yang biasanya terdapat di dalam hotel tempatnya luas dan memanjang.
Ruangannya tertutup dan dilayani oleh bartender dan beberapa waiter. Sangat cocok untuk tamu yang ingin rileks, mendengarkan musik sambil menikmati minumannya.

11. Bar and Restaurant

Biasanya terdapat di kota-kota. Bentuk dan dan tampilannya seperti restoran. Hanya saja khusus bar letaknya berada di sudut restoran dilengkapi dengan hiburan, seperti band untuk menghibur tamu-tamu yang sedang menikmati makanan dan minuman.

12. Dischotique Bar

Bar yang pada umumnya dibuka untuk pada malam hari dimana para tamu datang untuk menikmati music keras yang dimainkan oleh disc jokey (DJ) sambil minum minuman yang di bar. Bar ini tidak menjual makanan berat.

13. Night Club

Bar yang hanya dibuka pada malam hari. Ruangannya memiliki ukuran yang lebih luas dibanding jenis bar yang lain. Bisa jadi di dalam night club terdapat lebih dari satu bar dan menyediakan tempat untuk dance floor dan juga mempertunjukan hiburan seperti band atau life entertainment lainnya. Para tamu bisa menikmati minuman sampai larut malam.

14. Cocktail Bar

Bar ini menjual minuman yang sangat bervariasi, khususnya minuman-minuman campuran dengan standar minuman yang berkualitas. Bar ini biasanya, menyuguhkan hiburan-hiburan ringan seperti piano atau organ, trio guitar dan lain-lain.

\subsubsection{Barista}

Barista berasal dari bahasa italia yang berarti bartender, yang menyajikan berbagai jenis minuman yang tidak fokus kepada pembuatan kopi saja. Barista merupakan teman cerita dan berbagi ilmu dengan tamunya (Madakaty dalam Ramadhan, 2015:8). Barista tidak hanya belajar cara meracik kopi, tapi juga harus melatih hospitality dengan cara memberikan pelayanan terbaik bagi tamunya. Secara teknis, barista didefinisikan sebagai orang yang meracik kopi di balik mesin kopi. Barista memeiliki pengertian yang berbeda dengan brewers. Brewers hanya bertugas sebagai penyeduh kopi biasa dengan menggunakan alat seduh manual, seperti V60, kalita, dan frenchpress, barista meracik kopi dengan mesin kopi dan menyediakan menu lain yang berbahan dasar kopi, jadi barista mempunyai tugas yang lebih kompleks. 
Barista harus memiliki keahlian menyeduh kopi, baik menggunakan alat seduh manual maupun menggunakan mesin. Namun barista bukan hanya fokus terhadap alat yang digunakan, barista lebih fokus ke proses penyajian, barista bertanggungjawab menyampaikan rasa yang ingin disampaikan oleh kopi ke para tamunya. Barista juga harus memiliki pengetahuan yang dalam tentang kopi, karena barista bertanggungjawab menumbuhkan jumlah para penikmat kopi (Ramadhan, 2015:8). Ada beberapa syarat penting untuk menjadi barista, tidak membedakan umur dan kelamin (Ramadhan, 2015:9) Syarat menjadi barista ada tiga yaitu:

1. Keinginan Menjadi Barista.

Menurut para pelaku, seseorang barista harus diawali dengan keinginan karena dapat menentukan sikap dan proses apa yang kedepannya akan di pilih. Barista yang menekuni pekerjaan karena menjalankan suatu dengan tujuan yang harus di capai, ada yang ingin menjadi barista yang bertujuan untuk memenangkan kompetisi, bahkan ada juga yang mau menjadi barista hanya mencari keuntungan finansial. Bagi para pelaku barista, tujuan kedepannya bergantung pada niat awal mereka.

2. Menjadi Penikmat Kopi

Barista harus siap menjadi penikmat kopi karena setiap barista berintraksi dan merasakan kopi. Barista tidak boleh mudah bosan dan jenuh karena kopi itu sendiri dapat berubah-ubah setiap harinya jadi barista di tuntut untuk jadi penikmat kopi. Keunikan yang di miliki kopi membuatnya menarik untuk dipelajari setiap harinya.

3. Mempelajari Tentang Kopi.

Barista harus siap untuk mempelajari rumitnya kopi setiap harinya, sebuah teori umum yang berkembang di kalangan barista, dalam segelas kopi yang memenuhi standar terdapat peran barista $10 \%$, roaster $30 \%$ dan petani $60 \%$. Peran barista ini sangat kecil sekali, namun bagi para pelaku barista, peran kecil mereka lakukan ini memiliki tanggung jawab. Barista merupakan pelaku terdepan yang akan berinteraksi langsung dengan tamu, jadi barista memeiliki tanggung jawab yang paling besar. Tanpa sepuluh persen peran dari barista, kopi yang standar tidak akan pernah sempurna hasilnya. Para pelaku barista, menilai konsep dan kualitas barista berjalan beriringan karena keluhan sering sekali terjadi pada kualitas barista bukan pada konsep restoran, oleh karena itu harusnya konsep dan kualitas barista harus berkembang. Setiap hari berkutat di dunia kopi, tentunya membuat barista memaknai kopi lebih dari pada penikmat kopi dari biasanya. Bagi barista, kopi bukan lagi hanya sekedar cairan hitam yang memiliki banyak khasiat, kopi lebih dari itu. Bagi barista, kopi adalah suatu minuman keakraban masalah apapun daapat dibicarakan dengan ditemani secangkir kopi. Kopi juga dimaknai sebagai sebuah perjalanan-perjalanan panjang kopi hingga menjadi cairan hitam yang nikmat.

\subsubsection{Kinerja}

Kinerja (performance) merupakan perilaku organisasional yang berhubungan langsung dengan produksi barang atau penyampaian jasa, seringkali dipikirkan sebagai pencapaian tugas, istilah tugas sendiri berasal dari pemikiran aktivitas yang dibutuhkan oleh pekerja (Gibson dalam Rajagukguk, 2016:25). Kinerja adalah hasil kerja karyawan yang di nilai secara kualitas dan kuantitas sesuai dengan tugas dan tanggungjawab yang sudah diberikan untuk mencapai sebuah tujuan yang sudah di targetkan (Mangkunegara dalam Armediana dkk, 2013:3). Menurut Prawirosentono dalam Kurniawan (2014:178) faktor-faktor yang mempengaruhi kinerja karyawan sebagai berikut:

1. Efektivitas dan Efisiensi

Berhubungan dengan kinerja organisasi, maka ukuran baik buruknya kinerja diukur melalui efektivitas dan efisiensi. Dikatakan efektif apabila sudah mencapai tujuan, dikatakan efesiensi apabila hal itu memuaskan sebagai pendorong mencapai tujuan, terlepas apakah efektif atau tidak. Artinya, efektivitas dari kelompok apabila tujuan kelompok tersebut dapat dicapai sesuai dengan kebutuhan yang direncanakan.

2. Otoritas dan tanggung jawab

Organisasi yang baik adalah wewenang dan tanggung jawab telah diberikan dengan baik, tanpa adanya penundaan tugas. Masing-masing karyawan yang ada dalam organisasi mengetahui apa yang menjadi haknya dan tanggung jawabnya dalam rangka mencapai tujuan organisasi.

3. Disiplin

Secara umum, disiplin menunjukkan suatu kondisi atau sikap hormat yang ada pada diri karyawan terhadap peraturan dan ketetapan perusahaan. Disiplin merupakan ketaatan dan hormat terhadap perjanjian yang dibuat antara perusahaan dan karyawan

4. Inisiatif 
Inisiatif seseorang berkaitan dengan daya pikir, kreatifitas dalam bentuk ide untuk merencanakan sesuatu yang berkaitan dengan tujuan organisasi. Setiap inisiatif sebaiknya mendapat perhatian atau tanggapan positif dari atasan, kalau memang dia atasan yang baik.

\subsubsection{Keluhan Tamu}

Keluhan tamu diartikan sebagai sesuatu yang tidak menyenangkan atau sesuatu yang mengganggu chartered management Istitute mendefinisikan keluhan tamu sebagai suatu ungkapan kurang puas akan produk atau pelayanan baik lisan maupun tulisan dari pelanggan internal dan eksternal (LAN dalam Chandra, 2013:1). Perilaku keluhan konsumen adalah studi tentang bagaimana individu, kelompok, dan organisasi memilih, membeli, menggunakan, dan bagaimana barang, jasa, ide, atau pengalaman untuk memuaskan kebutuhan dan keinginan mereka (Kotler dan Keller dalam Chandra, 2013:1). Reaksi keluhan konsumen yang telah ditemukan terdiri dari berbagai tindakan termasuk keluhan langsung kepada perusahaan, berkata hal buruk perusahaan kepada teman atau keluarga, dan tidak loyal kemudian beralih ke perusahaan lain. Tidak semua konsumen mau melakukan keluhan langsung kepada perusahaan karena berbagai alasan seperti malas, sibuk, keluhan bakal dihiraukan, tidak percaya diri, dan lain-lain. Pada sebagian konsumen tertentu ada yang melakukan tindakan negatif yaitu mengatakan keburukan atau kejelekan dari suatu perusahaan kepada teman atau kerabatnya. Inilah konsumen yang membahayakan perusahaan. Word of mouth adalah salah satu teknik pemasaran yang lebih efektif untuk menarik konsumen secara tidak langsung (Chandra, 2013:4). Faktor penyebab perilaku keluhan konsumen bisa disebabkan oleh beberapa faktor seperti: ketidakpuasan, kepercayaan diri, sikap terhadap pengajuan keluhan, dan persepsi bahwa keluhan akan berhasil. Pelayanan yang buruk akan berdampak kepada perusahaan karena akan mengurangi jumlah konsumen yang datang berkunjung, pelayanan tidak bisa dihindari ketika sudah terjadi karena sifatnya spontan, pelayanan yang buruk akan berdampak pada tamu secara terus menerus dan berlangsung cepat, ketika karyawan memberikan pelayanan yang buruk pada saat berintraksi dengan tamu akan membuat tamu merasa tidak puas dan tidak akan kembali lagi (McCollough dalam Mensah, 2015:74).

\subsection{Metode Penelitian \\ 3.1.1. Desain Penelitian}

Desain penelitian ini menggunakan metode penelitian deskriptif kualitatif. Penelitian deskriptif kualitatif ditunjukan untuk mendeskripsikan dan menggambarkan fenomena-fenomena yang ada, baik bersifat alamiah maupun rekayasa manusia, yang lebih memperhatikan mengenai karaktaristik, kualitas, keterkaitan antar kegiatan (Syaodih dalam Esa, 2015:42). Penelitian deskriptif tidak memberikan perlakuan, manipulasi atau pengubahan pada variable-variabel yang di teliti, melainkan menggambarkan suatu kondisi yang apa adanya. Satu-satunya perlakuan yang diberikan hanyalah penelitian itu sendiri, yang di lakukan melalui teknik pengambilan data (Syaodih dalam Esa, 2015:42). Penulis menggunakan metode ini untuk mengetahui informasi tentang kinerja barista, mengidentifikasi keluhan tamu dan mendapatkan informasi tentang upaya peningkatan kinerja barista yang dapat digunakan untuk menciptakan atau mendeskripsikan mengenai Upaya Meningkatkan Kinerja Barista Untuk Mengurangi Keluhan Tamu Di Rock Gilis Coffee Lombok.

\subsubsection{Tehnik Pengambilan Data}

Metode pengumpulan data yang digunakan, meliputi:

1. Pengamatan (Observation)

Observasi yaitu melakukan pengamatan secara lansung ke objek penelitian untuk mengetahui cara dan kegiatan yang dilakukan (Riduwan, 2013:30). Penulis melakukan identifikasi terhadap kinerja barista untuk mengurangi keluhan tamu di Rock Gilis Coffee Lombok. Penulis melakukan observasi secara lansung mulai dari proses menyiapkan bahan minuman sampai menjadi minuman yang siap disajikan kepada tamu.

2. Wawancara

Wawancara adalah suatu cara pengumpulan data yang digunakan untuk memperoleh informasi langsung dari sumbernya (Subana dalam Riduwan,2013:29). Wawancara ini digunakan bila ingin mengetahui hal-hal dari responden secara lebih mendalam. Wawancara yang berlansung dengan owner, manager dan barista dengan membahas (SOP) yang ada di Rock Gilis Coffee dan membahas beberapa masalah yang sering terjadi di bar.

3. Studi Pustaka

Studi pustaka merupakan langkah awal dalam metode pengumpulan data. Studi pustaka merupakan metode pengumpulan data yang diarahkan kepada pencarian data dan informasi melalui dokumen- 
dokumen, baik dokumen tertulis, foto-foto, gambar, maupun dokumen elektronik yang dapat mendukung dalam proses penulisan. (Sugiyono dalam Stefanus, 2013:30). Penulis menggunakan beberapa buku tentang pariwisata dan perhotelan serta beberapa artikel dan jurnal dari internet sebagai acuan penulisan.

4. Dokumentasi

Dokumentasi adalah ditujukan untuk memperoleh data lansung dari tempat penelitian, meliputi buku-buku, peraturanperaturan, laporan kegiatan, foto-foto, film dokumenter, data yang relevan penelitian (Riduwan, 2013:31). Penelitian ini penulis mengambil foto dalam pembuatan produk dan foto selama operasional berjalan di Rock Gilis Coffee Lombok, brosur atau dokumen yang di dapat melalui persetujuan dari pihak manajemen.

\subsection{Pembahasan dan Hasil}

\subsubsection{Kinerja Barista di Rock Gilis Coffee}

Kinerja barista di Rock Gilis Coffee merupakan hasil atau tingkat keberhasilan seorang barista atau karyawan secara keseluruhan selama dalam melaksanakan tugasnya masing-masing baik secara kualitas maupun kuantitas dalam bekerja. Rock Gilis Coffee menilai kinerja barista mulai dari efisiensi dan efektifitas, kedisiplinan barista, tanggungjawab dan inisiatif dalam bekerja. Hasil kerja yang dapat dicapai barista harus sesuai dengan wewenang dan tanggungjawab yang sudah diberikan kepada masing-masing barista, hal ini merupakan suatu gambaran mengenai tingkat pencapaian pelaksanaan suatu kegiatan, program, kebijakan dalam mencapai sasaran, tujuan, visi dan misi perusahaan. Berdasarkan hasil pengamatan di Rock Gilis Coffee barista belum mencapai target yang diharapkan. Kinerja barista di Rock Gilis Coffee dinilai melalui empat unsur, kinerja yang langsung menyebabkan tamu mengajukan keluhan (Prawirosentono dalam Kurniawan, 2014: 178):

1. Efektifitas dan Efisiensi

Rock Gilis Coffee menilai kinerja barista kurang efektif dan efisien, adapun penyebab kurangnya efektifitas dan efisiensi barista dalam bekerja, yaitu:

a. Efektifitas

Efektifitas barista dalam bekerja kurang baik karena barista belum mampu memaksimalkan bahan dan peralatan yang sudah disediakan dan belum mampu membuat minuman yang memenuhi standar yang telah di terapkan sehingga barista belum bisa mencapai tujuan, contohnya:
1) Barista di Rock Gilis Coffee belum memiliki kemampuan dalam meracik minuman sehingga rasa minuman tidak sesuai dengan standar.

2) Barista kurang memahami dalam takaran sirup yang akan digunakan dalam mencampur minuman sehingga menimbulkan rasa manis yang berlebihan, hal ini yang menjadi penyebab dalam menjaga kualitas minuman belum tercapai.

3) Barista belum bisa memaksimalkan semua bahan dan peralatan yang telah disediakan oleh perusahaan sehingga ketika barista membuat minuman belum bisa memanfaatkan semua bahan yang ada.

b. Efisiensi

Efisiensi barista belum bisa memanfaatkan waktu dengan baik dalam bekerja dan kurang maksimal karena belum bisa mengatur waktu yang sudah ditetapkan, contohnya:

1) Barista belum mampu membuat minuman secara cepat, tepat dan hasil yang maksimal, ketika membuat tiga minuman sekaligus barista hanya memerlukan waktu enam menit, tetapi barista belum mampu mengatur waktu dengan baik sehingga bisa menghabiskan waktu sembilan-sepuluh menit. Penyebab barista membutuhkan waktu yang lama dalam membuat minuman adalah barista yang terlalu santai dalam membuat minuman, ketika barista membuat minuman shake dan blender barista memilih membuat minuman shake terlebih dahulu karena prosesnya lebih cepat, tetapi proses ini yang menyebabkan waktu membuat minuman menjadi lebih lama, seharusnya barista harus membuat minuman blender terlebih dahulu karena minuman yang menggunakan blender bisa berhenti secara otomatis dan bisa ditinggal untuk membuat minuman shake, jika barista membuat minuman shake terlebih dahulu, maka barista harus menunggu minuman sampai selesai diblender, hal ini yang 
menyebabkan efisiensi waktu dalam bekerja kurang maksimal.

2. Kedisiplinan

Kedisiplinan barista menjadi tolak ukur Rock Gilis Coffee dalam menilai kinerja barista, kedisiplinan barista di Rock Gilis Coffee belum memenuhi (SOP) yang di terapkan oleh pihak perusahaan, barista sering tidak mengikuti (SOP) seperti:

a. Datang Terlambat

Barista sering datang terlambat dalan bekerja, seharusnya barista harus datang lebih awal 30 menit sebelum operasional, supaya bisa mempersiapkan peralatan dan bahan yang akan digunakan sesuai dengan (SOP) yang sudah diterapkan.

b. Tidak Mengikuti Resep

Barista tidak disiplin dalam membuat minuman, barista sering tidak mengikuti sesuai resep dalam membuat minuman, sehingga rasa minuman menjadi tidak konsisten dan berubah-ubah.

c. Penyimpanan Bahan

Barista tidak memperhatikan dalam menyimpan buah yang mudah busuk dan tidak mudah busuk, barista menyimpan strawberry dan pisang di lemari es, pisang pada umumnya tidak bisa disimpan dalam lemari es karena akan mudah busuk, sedangkan strawberry harus disimpan di tempat lebih dingin agar tidak mudah busuk, hal ini harus diperhatikan oleh barista dalam membedakan mana bahan yang mudah busuk dan tidak mudah busuk.

3. Tanggung Jawab

Barista belum bisa bertanggungjawab dalam menjaga dan merawat peralatan maupun dalam penyimpanan bahan minuman, contohnya:

a. Merawat dan Menjaga Peralatan

Barista sering lalai dalam menjaga peralatan minuman seperti gelas banyak pecah, mesin kopi dan peralatan lainnya jarang dibersihkan, sehingga secara perlahan peralatan yang digunakan akan berkurang dan rusak, barista belum bisa mempunyai rasa memiliki terhadap peralatan yang digunakan sehari-hari, hal ini menyebabkan kerugian terhadap perusahaan.

b. Memeriksa Bahan

Barista kurang teliti ketika memeriksa bahan, barista kurang memperhatikan tanggal kadaluawarsa bahan seperti sirup, jus dan konsentrat, barista harus selalu mengecek bahan minuman, ketika barista menemukan bahan yang hampir kadaluawarsa supaya minuman dari bahan tersebut agar di jual lebih cepat. .

4. Inisiatif

Inisiatif seseorang berkaitan dengan daya pikir, kreatifitas dalam bentuk ide, barista di Rock Gilis Coffee masih belum bisa berkreasi atau berkarya terhadap minuman yang di buat seperti:

a. Penyajian Minuman

Barista kurang kreatif dalam menyajikan minuman seperti pembuatan garnis untuk mocktail, barista hanya menggunakan garnis yang sama setiap hari pada mocktail sehingga terlihat begitu saja dan membosankan, begitu juga dengan kopi barista kurang ada kreatifitas dalam membuat latte art pada kopi, latte art adalah karya seni yang di gambar di atas kopi, hal ini juga menarik perhatian dari tamu, tetapi barista hanya membuat gambar latte yang sama setiap harinya, sehingga perlu adanya kreatifitas dan karya dalam menyajikan minuman kopi ataupun mocktail agar terlihat lebih bagus, tamu lebih tertarik dengan minuman tersebut karena tampilan yang beda dari sebelumnya sehingga tidak membosankan.

b. Menu Promosi

Barista di Rock Gilis Coffee tidak mempunyai inisiatif menawarkan menu minuman baru kepada tamu yang dine in maupun tamu yang take away, sehingga tamu tidak mengetahui menu baru dan hanya mengetahui minuman yang biasa tamu pesan, seharusnya barista memperkenalkan minuman baru supaya tamu mengetahui jika Rock Gilis Coffee punya beragam minuman, sehingga semua minuman bisa terjual dengan rata tidak hanya minuman favorit saja.

5. Motivasi

Kurangnya motivasi yang didapatkan barista dari perusahaan membuat rasa peracaya diri dan tidak ada semangat untuk bekerja, hal ini sangat diperlukan untuk menunjang kinerja menjadi lebih baik kedepannya supaya barista lebih fokus dan mempunyai semangat yang tinggi untuk bekerja.

6. Pelatihan

Pihak perusahaan tidak memberikan pelatihan kepada barista, sehingga barista 
tidak terlalu mengerti bagaiman cara bekerja sesuai dengan standar operasional yang telah diterapkan oleh perusahaan, selain itu barista juga tidak mengerti tata cara meracik minuman dengan baik karena barista mempunyai pengetahuan dan kemmpuan yang sedikit dalam meracik minuman.

7. Breafing

Rock Gilis Coffee tidak melakukan breafing secara rutin karena akan menyebabkan barista tidak mengetahui bagaimana perkembangan restoran, ketika pihak perusahaan mengadakan briefing maka semua yang berkaitan dengan bar akan dibahas seperti masalah yang sering terjadi, target yang belum tercapai dan operasional yang tidak berjalan lancar, sehingga barista akan tau apa yang harus dilakukan supaya bisa meningkatkan kinerja dalam bekerja dan bisa mencapai target sesuai yang diinginkan perusahaan.

\subsubsection{Keluhan Tamu Di Rock Gilis Coffee}

Keluhan tamu pada dasarnya disampaikan langsung secara lisan atau berbicara lansung kepada barista, selain tamu menyampaikan secara tulisan melalui guest comment yang sudah disediakan oleh perusahaan, keluhan tamu tidak bisa diabaikan karena akan membuat tamu merasa tidak dihargai dan tidak mendapatkan perhatian dari barista. Mengatasi persaingan dan menjaga kepuasan, perusahaan secara efektif berusaha meningkatkan efisiensi dan meningkatkan tamu tanpa mengorbankan kualitas layanan (Sabharwal dkk dalam Mensah, 2015:74). Beberapa faktor yang menimbulkan keluhan terjadi yang di sebabkan oleh perusahaan maupun karyawan (Kasavana \& Brooks dalam Mensah, 2015:74), yaitu:

\section{Service Complaint}

Keluhan ini adalah jenis keluhan tentang pelayanan yang kurang baik dari karyawan terhadap tamu di Rock Gilis Coffee. Beberapa keluhan tentang pelayanan di Rock Gilis Coffee, diantaranya:

a. Pelayanan Barista

Sebagian besar tamu mengeluhkan pelayanan barista yang kurang baik, kebanyakan barista jarang berhadapan langsung dengan tamu, melainkan hanya berada di bar dan membuat minuman, tetapi tamu juga membutuhkan barista ketika rasa minuman tamu tidak sesuai dengan yang diharapkan, pada saat kondisi seperti ini, tamu membutuhkan pelayanan seperti memberikan penyajian kepada tamu dengan baik dan memberikan respon yang baik kepada tamu karena tamu juga membutuhkan barista untuk menceritakan tentang minuman yang tamu pesan, barista juga berperan sebagai teman bagi tamunya seperti, barista menceritakan tentang kualitas kopi yang tamu pesan dan meyakini jika tamu mendapatkan kualitas kopi yang terbaik, sehingga tamu merasa diperhatikan oleh barista.

b. Quality Chek

Barista dan Waiter jarang melakukan quality chek terhadap minuman yang dikeluarkan, sehingga barista tidak mengetahui apakah tamu sudah mendapatkan minuman yang sesuai dengan keinginan atau belum, barista atau waiter harus melakukan quality check terhadap minuman yang dikeluarkan, hal ini berkaitan dengan kepuasan tamu ketika barista atau waiter sudah memastikan jika tamu mendapatkan apa yang diinginkan otomaits tamu akan mendapat kepuasan dari pelayanan karena merasa diperhatikan.

\section{Attitudinal Complaint}

Attitudinal Complaint adalah jenis keluhan yang mengarah kepada kinerja karyawan, kurangnya kemampuan barista dalam membuat suatu minuman termasuk dalam Attitudinal Complaint yang terjadi di Rock Gilis Coffee adapun beberapa masalah yang sering dikeluhkan oleh tamu terkait dengan kinerja barista yaitu:

\subsubsection{Upaya Meningkatkan Kinerja Barista untuk Mengurangi Keluhan Tamu Di Rock Gilis Coffee}

Keberhasilan bar bergantung kepada barista sebagai pelaku utama dalam operasional, peranan barista sangat penting dalam meningkatkan kinerja dan mengurangi keluhan tamu di Rock Gilis Coffee sehingga dapat meningkatkan nama baik restoran, oleh karena itu barista memerlukan ilmu pengetahuan lebih dalam tentang kinerja yang sesuai standar operasional agar dapat mengurangi keluhan tamu. Adapun cara mengurangi keluhan tamu di Rock Gilis Coffee, yaitu:

1. Meningkatkan Kinerja Barista

Pada dasarnya kinerja yang baik adalah mengikuti prosedur sesuai standar yang telah ditetapkan oleh pihak perusahaan, kinerja tersebut harus memiliki produktifitas lebih, sehingga apa yang diharapkan oleh pihak perusahaan bisa di capai sesuai dengan target yang sudah 
ditentukan. Ada beberapa cara untuk meningkatkan kinerja barista, yaitu:

a. Meningkatkan efektifitas dan efisiensi

b. Meningkatkan Kedisiplinan

Barista harus lebih disiplin dalam bekerja demi tercapainya operasional yang lancar, barista harus memperhatikan jam kerja supaya datang tepat waktu dan bisa mempersiapkan alat-alat yang akan digunakan, barista juga harus mengikuti resep sesuai dengan (SOP) sehingga menu minuman yang sama tidak memiliki rasa yang berbeda, penyimpanan bahan minuman juga harus di perhatikan, ketika barista menyimpan bahan minuman agar bisa membedakan tempat untuk bahan minuman yang mudah rusak dan yang tahan lama sesuai dengan (SOP) yang berlaku sehingga bahan minuman bisa digunakan di hari berikutnya.

c. Bertanggung Jawab

Barista harus lebih peduli terhadap peralatan yang digunakan supaya bisa dijaga dan dirawat sebaik mungkin agar peralatan tidak akan cepat rusak maupun pecah dan bisa di pergunakan lebih lama.

d. Inisiatif

Barista kurang kreatif dalam menyajikan kopi atau penyajian minuman lainnya, barista harus punya inisiatif untuk bisa berkreasi dan berkarya dalam menyajikan minuman supaya lebih menarik dan tidak membosankan bagi tamu, barista juga harus mempunyai inisiatif dalam menawarkan promosi sehingga tamu mengetahui berbagai macam rasa dan beragam minuman supaya tamu tidak bosan dengan rasa dan menu minuman yang begitu-gitu saja.

e. Meningkatkan Kualitas Minuman

Barista harus memperhatikan minuman yang akan disajikan kepada tamu, sebelum disajikan hendaknya barista memastikan apakah minuman yang akan dikeluarkan sudah memenuhi standar atau belum, dalam proses pembuatan minuman barista diharuskan mengikuti resep dan prosedur yang sudah disediakan oleh pihak perusahaan agar rasa minuman tidak berubah-ubah dan memiliki rasa yang sama sehingga tidak menimbulkan keluhan tamu yang sudah terbiasa memesan minuman yang sama namun dengan rasa yang berbeda-beda, upaya ini dilakukan untuk menjaga nama baik perusahaan dan tidak kehilangan tamu yang sudah menjadi pelanggan tetap.

f. Meningkatkan Pelayanan

Barista tidak hanya bertugas sebagai peracik kopi atau minuman lain, barista juga bertugas sebagai pelayan utama bagi tamu karena kopi atau minuman yang mereka buat itu adalah tanggung jawab barista. Barista harus memberikan kesan yang baik bagi tamu yang datang berkunjung, sehingga tamu merasa puas dan nama perusahaan akan menjadi lebih meningkat, untuk menunjang kulitas pelayanan barista harus menguasai aturan dan tata cara pelayanan minuman yang berlaku di bar seperti, penyambutan, komunikasi yang baik dengan tamu, dan barista harus selalu peduli dengan tamu. Hal ini akan mengurangi keluhan-keluhan yang terjadi sehingga tamu merasa nyaman, puas dan datang berkunjung kembali.

g. Memberikan Motivasi

Barista harus diberikan motivasi oleh atasan setiap harinya sehingga bisa meningkatkan rasa semangat dan percaya diri barista dalam bekerja supaya bisa bekerja dengan fokus dan mengurangi kesalahan, selain itu barista juga akan merasa mudah dalam bekerja sesperti tidak ada hambatan ketika mendapatkan motivasi dari atasan.

h. Mengadakan Pelatihan

Barista harus mendapatkan pelatihan setiap bulan supaya barista mengerti bagaimana cara bekerja dengan baik dan mempunyai wawasan dan kemampuan lebih dalam meracik minuman sehingga dengan pelatihan barista akan sangat terbantu dalam operasional sebagaimana semestinya dan sesuai dengan standar operasional yang telah diterapkan oleh perusahaan.

i. Breafing

Pihak perusahaan harus rutin mengadakan breafing bagi semua barista yang bertujuan untuk mengetahui apa saja masalah yang terjadi di bar dan target apa saja yang belum tercapai sehingga barista tau apa yang harus dikerjakan supaya target dan masalah bisa terselesaikan, selain itu barista juga bisa memberikan masukan kepada pihak perusahaan terkait dengan masalah 
yang terjadi sehingga mempunyai jalan yang sama dan satu tujuan.

\subsection{Kesimpulan}

Berdasarkan penelitian di Rock Gilis

Coffee dapat disimpulkan sebagai berikut:

1. Kinerja barista di Rock Gilis Coffee Lombok masih kurang baik. Barista masih kesulitan dalam meningkatkan kedisiplinan, tanggung jawab, inisiatif, efektifitas dan efisiensi dalam bekerja. Beberapa barista juga belum memahami sistem kerja dan masih melanggar standar operasional, sehingga kinerja barista masih belum maksimal.

2. Barista di Rock Gilis Coffe masih belum mampu memberikan pelayanan yang optimal, sehingga memunculkan beberapa keluhan dari tamu, diantaranya:

a. Pelayanan barista

Pelayanan barista yang masih kurang baik seperti penyajian terhadap tamu, kurang peduli terhadap tamu dan sering mengabaikan ketika tamu membutuhkan bantuan, sehingga masih menimbulkan terjadinya keluhan dari tamu, hal ini membuat tamu merasa tidak diperhatikan dan kurang baik ketika dilayani oleh barista.

b. Kualitas Minuman

Kualitas minuman masih dibawah standar, hal ini dikarenakan oleh barista tidak mengikuti (SOP) dan tidak mengikuti resep minuman, sehingga menimbulkan keluhan dari tamu karena rasa minuman yang tamu dapatkan tidak sesuai dengan minuman yang tamu harapkan.

3. Upaya peningkatan kinerja barista untuk mengurangi keluhan tamu yang dilakukan perusahaan, diantaranya:

a. Meningkatkan Kinerja Barista

Upaya peningkatan kinerja barista belum dapat berjalan dengan baik karena barista tidak mengikuti (SOP) dalam bekerja, penghambat dari peningkatan kinerja juga dipengaruhi oleh barista yang kurang disiplin, bertanggungjawab, inisiatif, efisien dan efektifitas, motivasi, pelatihan, dan briefing secara rutin yang masih kurang, sehingga menyebabkan kinerja barista masih kurang maksimal.

b. Mengurangi Keluhan Tamu

Upaya barista untuk mengurangi keluhan tamu masih kurang maksimal, hal itu dikarenakan barista belum dapat meningkatkan pelayanan serta kualitas minuman, masalah ini yang mengakibatkan terjadinya keluhan dari tamu karena tamu tidak mendapatkan pelayanan yang baik dan tidak mendapatkan rasa minuman yang sesuai.

\section{Daftar Pusataka}

[1] Armediana, Sukmarwati, Suryaningsih, Margarehra dan hayu, ida. 2013. Analisis Kinerja Pegawai Di Kecamatan Gunungpati Semarang. Jurnal Of Public Policy And Management Review, II(2), 34. $\mathrm{Di}$ Ambil Dari: https://media.neliti.com/media/publication s/94397-ID-analisis-kinerja-pegawai-dikecamatan-gu.pdf . (20 April 2018).

[2] Brahmanto, Erlangga, Hermawan, Ari, Hamzah, Faisal.2018. Manajemen Hospitality. Pekalongan: NEM.

[3] Chandra, Billy Archie. 2013. Faktor-faktor Yang Mempengaruhi Komplain Perilaku Konsumen. Di Ambil Dari: http://ejournal.uajy.ac.id/4337/1/0EM17643.pdf (22 April 2018)

[4] Darwin, Durachim, Endang dan Hamzah Faizal. 2017. Restoran Bisnis Berbasis Standar Kompetensi. Jurnal Pariwiasata, IV(4), $12 \quad \mathrm{Di} \quad$ Ambil Dari.: http://ejournal.bsi.ac.id/ejurnal/index.php/j p/article/view/1701/1340 (8 Juli 2018)

[5] Esa, Yusti. (2015). Pembentukan Karakter Peserta Didik Melalui Penyelenggara Kantin Kejujuran Di SD Negeri Tiga Purwodadi Kecamatan Tambak Kabupaten Banyumas. Di Ambil Dari: http://eprints.uny.ac.id/14815/3/BAB\%20II I.pdf (26 April 2018)

[6] Kurniawan, Gultom, Dedek. 2014. Pengaruh Budaya Organisasi Perusahaan Dan Motivasi Terhadap Kinerja Karyawan Pada PT. Perusahaan Gas Negara (Persero) Tbk Medan. Jurnal Ilmiah Manajemen dan Bisnis, XIV(14), 17-18. Di Ambil Dari: http://jurnal.umsu.ac.id/index.php/mbisnis/ article/view/194/132 (3Mei 2018).

[7] Mensah, Ishmael Adelaide, MensahKufuor, Edem Kwesi Amenumey.2015. Service Failures in 3- to 5-Star Hotels in Accra, Ghana. Journal of Tourism and Hospitality Management, III(3), 74 Di Ambil

Dari: https://www.researchgate.net/publication/ 284546353_Service_Failures_in_3-_to_5Star_Hotels_in_Accra_Ghana. $(21$ Mei 2018).

[8] Setyawan Andang, Wahyu. (2017). Identifikasi Kemampuan Flair Bartending 
Pada Komunitas Bartender di Yogyakarta. Di Ambil Dari: http://eprints.uny.ac.id/53786/1/Andang\% 20Wahyu\%20Setyawan\%20\%281151124 4021\%29.pdf (25 April 2018).

[9] Putri,Emmita Devi Hari.2016.pengantar akomodasi dan restoran. Yogyakarta: depublish.

[10] Ramadhan, Fakhri. 2017. Makna Kerja Barista. Di Ambil Dari: https://dspace.uii.ac.id/bitstream/handle/1 23456789/5344/Jurnal_Fakhri\%20Ramad han (11 April 2018).

[11] Rajagukguk,Peter.2016. Pengaruh Motivasi Dan Komitmen Organisasi Terhadap Kinerja Pegawai. Ecodenica, IV(4), 25. Di Ambil Dari: http://ejournal.bsi.ac.id/ejurnal/index.php/e codemica/article/view/283/pdf (8 Juli 2016).

[12] Riduwan.2013.Skala Pengukuran Variabel-Variabel Penelitian. Bandung: Alfabeta.

[13] Stefanus, Ganang.2013. Analisis Deskriptif Faktor-Faktor Yang Memengaruhi Kenyamanan Membaca Pemustaka (Studi Kasus Pemustaka di
UPT Perpustakaan Politeknik Negeri Semarang). Di Ambil Dari: http://eprints.undip.ac.id/40985/3/BAB_III. pdf (6 mei 2018).

[14] Sumarsono, Dicky. 2015. Semua Orang Bisa Menjalankan Luar Biasa Bisnis Restoran Di Indonesia. Jakarta: PT Gramedia Pustaka Utama.

[15] Yanti, Haryono Andi Tri dan Minarsih Maria Magdalena.2015. Pengaruh Kompensasi , Motivasi Kerja, Lingkungan kerja dan disiplin terhadap Kinerja Karyawan pada CV Koperasi Puri Kencana Taksi Semarang. Journal Of Management, I(1), 10. Di Ambil Dari: http://jurnal.unpand.ac.id/index.php/MS/ar ticle/view/271/267 (3 Mei 2018).

[16] Yulianto, Atun. 2016. Kinerja Pengembangan Dan Pelayanan Candi Ratu Boko Dalam Mendukung Kesempatan Usaha Masyarakat Setempat. Jurnal Khasanah IImu, VII(7), 13. $\mathrm{Di}$ Ambil Dari: http://ejournal.bsi.ac.id/ejurnal/index.php/k hasanah/article/view/473/366 s(6 Mei 2018). 